\title{
Slowing chronic kidney disease progression: should we be looking beyond mean blood pressure?
}

\author{
Keith M Diaz and Praveen Veerabhadrappa \\ Hypertension Research (2013) 36, 112-114; doi:10.1038/hr.2012.167; published online 11 October 2012
}

\begin{abstract}
Cingly hronic kidney disease $(\mathrm{CKD})$ is increasingly being recognized as a major global public health concern. This is perhaps best evidenced by the establishment of World Kidney Day, which has been observed annually since its inauguration in March of 2006. Preceding this global CKD awareness campaign, the introduction of the Kidney Disease Outcomes Quality Initiative of the National Kidney Foundation in February of 2002 propagated an important global shift towards the recognition of CKD as a worldwide public health problem that should be screened and managed by clinicians. ${ }^{1}$ Although we have a better understanding of the alarming incidence and prevalence of CKD in various world populations as a result of these efforts, effective treatment strategies to slow or even halt the progression of CKD are still limited. Presently, once significant impairment of renal function has occurred, the progression of CKD toward end-stage renal disease (ESRD) tends to occur irrespective of pharmacologic treatment in many individuals. Thus, although current treatment guidelines have undeniably been beneficial in reducing the incidence of ESRD, there is much still to be discerned regarding the effective treatment of CKD.

Hypertension is one of the leading factors that contributes to the progressive decline of renal function leading to ESRD, and thus has become an important target in the treatment of CKD. Current guidelines recommend a target clinic blood pressure (BP) of $<130 / 80 \mathrm{~mm} \mathrm{Hg}$ for patients with $\mathrm{CKD}^{2}$ These guidelines stem from findings from
\end{abstract}

Dr KM Diaz is at the Center for Behavioral Cardio vascular Health, Department of Medicine, Columbia University Medical Center, New York, NY, USA $\mathrm{P}$ Veerabhadrappa is at the Department of Exercise Science, College of Education and Human Services, Shippensburg University, Shippensburg, PA, USA.

E-mail: kd2442@columbia.edu observational studies and clinical trials that suggest that lowering mean BP may slow or retard the progression of $\mathrm{CKD}$ and reduce concurrent cardiovascular risk. ${ }^{3-6}$ However, several large-scale randomized controlled trials have reported that there is no significant beneficial effect of intensive BP lowering of $<130 / 80 \mathrm{~mm} \mathrm{Hg}$ for patients with $\mathrm{CKD}^{7,8}$ From these latter findings, it has been suggested that once mean BP is lowered to a given level, additional reductions do not confer greater protection against CKD progression. ${ }^{8}$ Although the lowering of $\mathrm{BP}$ is still regarded as one of the main goals for CKD treatment despite these findings, nonetheless they raise questions as to what is the most effective pharmacologic approach for treating BP in CKD patients.

In recent years, data have accumulated to indicate that changes or fluctuations in BP values across weekly, monthly or yearly clinic visits may have prognostic value that is equal to or greater than that of mean BP. In a retrospective analysis of 22576 patients with essential hypertension enrolled in the International Verapamil-Trandolapril Study trial, it was found that for a given mean BP level, there was an inverse relationship between the risk of cardiovascular morbidity and mortality, and the percentage of clinic visits in which BP was found to be controlled (that is, $<140 / 90 \mathrm{~mm} \mathrm{Hg}$ ). From these findings, it was concluded that focusing not only on mean $\mathrm{BP}$, but also on the proportion of visits in which BP was controlled may improve the assessment of the protective effect of BP-lowering interventions on patient outcome. ${ }^{9}$ In a more comprehensive analysis in which the visit-to-visit changes in BP were quantified as an index of variability (e.g., visit-to-visit BP variability), retrospective analysis of both the UK-TIA aspirin trial and Anglo-Scandinavian Cardiac
Outcomes Trial (ASCOT) by Rothwell et al. ${ }^{10}$ showed that visit-to-visit variability in systolic BP over the course of five or seven clinic visits predicted stroke/coronary events to a much greater extent than mean BP. Furthermore, in two separate retrospective analyses of randomized controlled trials, it was shown that the treatment regimens associated with lower visit-to-visit variability in systolic BP were also associated with a lower incidence of stroke and accounted for more of the effects of treatment efficacy on stroke risk than did effects on mean BP. ${ }^{11,12}$ These findings have led some to suggest that pharmacologic therapy targeting BP should reduce mean BP without increasing BP variability, and ideally should reduce both. ${ }^{11}$ In light of these findings, the question as to whether visit-to-visit BP variability should be a target in CKD management may be worth exploring as it could help to explain previous study findings that reported a lack of additional benefits with aggressive BP lowering and could help to provide direction as to the optimal pharmacologic regimens for CKD treatment.

In this issue of Hypertension Research, Yokota et al. ${ }^{13}$ investigate for the first time the longitudinal effect of visit-to-visit BP variability on the progression of $\mathrm{CKD}$. They report that the variability in $\mathrm{BP}$ across 12 consecutive visits taken over a median of 24 months was an independent predictor of the slope of decline in estimated glomerular filtrate rate (eGFR). They furthermore showed that the risk for composite renal end points (doubling of serum creatinine or need for dialysis) doubled for each $1 \mathrm{~mm} \mathrm{Hg}$ increase in the visit-to-visit variability of systolic BP. Perhaps more surprisingly, they show that mean BP was not a predictor of the eGFR slope or composite renal end points after adjustment 
for covariates in this cohort of patients with non-diabetic CKD. Taken together, these findings may provide some evidence that visit-to-visit BP variability is associated with the progression of non-diabetic CKD. Of course, given the small size of the study cohort $(n=56)$, these findings will need to be confirmed in much larger clinical trials. Nonetheless, they do shed light on a potential therapeutic target in CKD that extends beyond the conventional management of mean BP.

Although the findings presented by Yokota et al. are interesting and certainly could suggest that clinicians should be paying attention to more than just mean $\mathrm{BP}$ when treating $\mathrm{CKD}$, their findings perhaps raise more questions than answers. First, what are the mechanisms by which large fluctuations in BP contribute to the progressive deterioration of renal function? Data from several cross-sectional studies have reported an association between visit-to-visit BP variability and alterations in the structure and function of the vasculature, which might suggest that increased variability in BP could contribute to the pathogenesis of vascular dysfunction in the renal microvascular. ${ }^{14,15}$ Alternatively, it is plausible that visit-to-visit variability in BP could simply be the manifestation of inconsistent medication adherence. Unfortunately, measures of vascular structure/ function and medication adherence were not assessed in the present study; thus the precise mechanisms remain to be elucidated. Second, when is a patient considered to have high visit-to-visit BP variability that mandates treatment? Yokota et al. attempted to address this issue in their study using the Youden Index to identify a clinical cut point for the visit-to-visit variability in systolic BP. They identified the cutoff value of $14.8 \mathrm{~mm} \mathrm{Hg}$ as an indicator of the composite renal end points with a sensitivity and specificity of $86 \%$ and 63\%, respectively. Nonetheless, the low sample size in their study and the moderate level of specificity for predicting composite renal end points limits this cut point's clinical relevance. Third, how frequently should BP be measured? Several studies on visit-to-visit BP variability have shown that the variability in BP quantified from annual visits is associated with clinical outcomes; ${ }^{16,17}$ whereas others have reported visit-to-visit variability quantified from visits spanning a period of weeks to months is associated with clinical outcomes. ${ }^{10,18,19}$ Unfortunately, this question could not be addressed adequately, given the retrospective nature of the study by Yokota et al., as the duration between clinic visits was not static within-subjects or between-subjects. Nonetheless, one could infer from their findings that the frequency of visits is not a confounding factor as the association of visit-to-visit BP variability with measures of CKD progression remained significant after adjustment for the mean duration between visits in multivariate models. It is worth noting, however, that a previous study by Okada et al. ${ }^{20}$ reported that the day-to-day variability in BP measured over 7 consecutive days with a home BP monitoring device was not associated with CKD progression in a cohort of 135 patients with stage 3-5 CKD. Whether the conflicting results from these two studies is a result of differences in study population or whether it might suggest that changes in BP over a period of months carries greater prognostic value in CKD than changes in BP over a period of days is still unclear. Finally, if both mean BP and BP variability should be targeted for pharmacologic treatment in CKD patients, what type of antihypertensive drug or drug combination would carry the greatest therapeutic effect? In the study by Yokota et al., although the use of calcium channel blockers was associated with the steepest declines in eGFR, no differences were reported in visit-to-visit BP variability across drug classes. Thus, their findings provide little evidence or insight as to whether the effects of pharmacologic treatment on visit-to-visit BP variability confers any benefit. It should be acknowledged, however, that the study was grossly underpowered to appropriately investigate drug class effects.

In conclusion, whether we should consider visit-to-visit BP variability as an additional target for antihypertensive treatment in CKD patients, along with the reductions in mean BP, still remains unclear and the available evidence is not strong enough to support such a conclusion. Findings from experimental studies in animal models have reported that reductions in BP variability by various antihypertensive treatment regimens are associated with organ protection of the heart, kidneys and aorta, independent of effects on mean $\mathrm{BP}^{21-23}$ However, evidence that BP variability reduction from antihypertensive treatment improves prognosis in CKD in human subjects presently does not exist. The study by Yokota et al. provides important information about an emerging cardiovascular risk factor and presents some of the first evidence that visit-to-visit BP variability may have clinical or prognostic value in CKD. The many questions that their findings raise warrants further investigation, perhaps starting with re-analysis of large-scale observational studies and randomized controlled trials.

\section{CONFLICT OF INTEREST}

The authors declare no conflict of interest.

1 National Kidney Foundation. Kidney Disease Outcome Quality Initiative (K/DOQI) clinical practice guidelines for chronic kidney disease: evaluation, classification, and stratification. Am J Kidney Dis 2002; 39: S1-266.

2 Chobanian AV, Bakris GL, Black HR, Cushman WC, Green LA, Izzo JL, Jones DW, Materson BJ, Oparil S, Wright JT, Roccella EJ. Seventh report of the joint national committee on prevention, detection, evaluation, and treatment of high blood pressure. Hypertension 2003; 42: 1206-1252.

3 Klag MJ, Whelton PK, Randall BL, Neaton JD, Brancati $\mathrm{FL}$, Stamler J. End-stage renal disease in africanamerican and white men. 16-Year MRFIT findings. JAMA 1997; 277: 1293-1298.

4 Klahr S, Levey AS, Beck GJ, Caggiula AW, Hunsicker L, Kusek JW, Striker G. The effects of dietary protein restriction and blood-pressure control on the progression of chronic renal disease. Modification of diet in renal disease study group. N Engl J Med 1994; 330: 877-884.

5 Peterson JC, Adler S, Burkart JM, Greene T, Hebert LA, Hunsicker LG, King AJ, Klahr S, Massry SG, Seifter JL. Blood pressure control, proteinuria, and the progression of renal disease. The modification of diet in renal disease study. Ann Intern Med 1995; 123: 754-762.

6 Tozawa M, Iseki K, Iseki C, Kinjo K, Ikemiya Y, Takishita S. Blood pressure predicts risk of developing end-stage renal disease in men and women. Hypertension 2003; 41: 1341-1345.

7 Uzu T, Kida Y, Yamauchi A, Kume S, Isshiki K, Araki S, Koya D, Haneda M, Kashiwagi A, Maegawa H, Kikkawa $R$. The effects of blood pressure control levels on the renoprotection of type 2 diabetic patients without overt proteinuria. J Am Soc Hypertens 2012; 6: 124-131.

8 Wright Jr JT, Bakris G, Greene T, Agodoa LY, Appel LJ, Charleston J, Cheek D, Douglas-Baltimore JG, Gassman J, Glassock R, Hebert L, Jamerson K, Lewis J, Phillips RA, Toto RD, Middleton JP, Rostand SG. Effect of blood pressure lowering and antihypertensive drug class on progression of hypertensive kidney disease: results from the AASK trial. JAMA 2002; 288: 2421-2431.

9 Mancia G, Messerli F, Bakris G, Zhou Q, Champion A, Pepine CJ. Blood pressure control and improved cardiovascular outcomes in the international verapamil srtrandolapril study. Hypertension 2007; 50: 299-305.

10 Rothwell PM, Howard SC, Dolan E, O'Brien E, Dobson JE, Dahlof B, Sever PS, Poulter NR. Prognostic significance of visit-to-visit variability, maximum systolic blood pressure, and episodic hypertension. Lancet 2010; 375: 895-905.

11 Rothwell PM, Howard SC, Dolan E, O'Brien E, Dobson JE, Dahlof B, Poulter NR, Sever PS, Ascot B. Effects of beta blockers and calcium-channel blockers on withinindividual variability in blood pressure and risk of stroke. Lancet Neurol 2010; 9: 469-480.

12 Webb AJ, Fischer U, Mehta Z, Rothwell PM. Effects of antihypertensive-drug class on interindividual variation in blood pressure and risk of stroke: a systematic review and meta-analysis. Lancet 2010; 375: 906-915.

13 Yokota K, Fukuda M, Matsui Y, Hoshide S, Shimada K, Kario K. Impact of visit-to-visit variability of blood pressure on deterioration of renal function in patients with non-diabetic chronic kidney disease. Hypertens Res 2013; 36: 151-157.

14 Diaz KM, Veerabhadrappa P, Kashem MA, Feairheller DL, Sturgeon KM, Williamson ST, Crabbe DL, Brown MD. Relationship of visit-to-visit and ambulatory blood pressure variability to vascular function in Africal Americans. Hypertens Res 2012; 35: 55-61.

15 Nagai M, Hoshide S, Ishikawa J, Shimada K, Kario K. Visit-to-visit blood pressure variations: new independent determinants for carotid artery measures in the 
elderly at high risk of cardiovascular disease. J Am Soc Hypertens 2011; 5: 184-192.

16 Kilpatrick ES, Rigby AS, Atkin SL. The role of blood pressure variability in the development of nephropathy in type 1 diabetes. Diabetes Care 2010; 33: 2442-2447.

17 Shimbo D, Newman JD, Aragaki AK, Lamonte MJ, Bavry AA, Allison M, Manson JE, Wassertheil-Smoller $\mathrm{S}$. Association between annual visit-to-visit blood pressure variability and stroke in postmenopausal women: Data from the women's health initiative. Hypertension 2012; 60: 625-630.

18 Hsieh YT, Tu ST, Cho TJ, Chang SJ, Chen JF, Hsieh MC Visit-to-visit variability in blood pressure strongly predicts all-cause mortality in patients with type 2 diabetes: a 5.5-year prospective analysis. Eur J Clin Investig 2012; 42: 245-253.

19 Muntner P, Shimbo D, Tonelli M, Reynolds K, Arnett DK, Oparil S. The relationship between visit-to-visit variability in systolic blood pressure and all-cause mortality in the general population: findings from NHANES III, 1988 to 1994. Hypertension 2011; 57: 160-166.

20 Okada T, Matsumoto H, Nagaoka Y, Nakao T. Association of home blood pressure variability with progression of chronic kidney disease. Blood Press Monit 2012 17: $1-7$
21 Du WM, Miao CY, Liu JG, Shen FM, Yang XQ, Su DF. Effects of long-term treatment with ketanserin on blood pressure variability and end-organ damage in spontaneously hypertensive rats. I Cardiovasc Pharmacol 2003; 41: 233-239.

22 Liu JG, Xu LP, Chu ZX, Miao CY, Su DF. Contribution of blood pressure variability to the effect of nitrendipine on end-organ damage in spontaneously hypertensive rats. J Hypertens 2003; 21: 1961-1967.

23 Xie HH, Zhang XF, Chen YY, Shen FM, Su DF. Synergism of hydrochlorothiazide and nifedipine on blood pressure variability reduction and organ protection in spontaneously hypertensive rats. Hypertens Res 2008; 31: 685-691. 